\title{
The Magnitude of HIV/AIDS Problem vis-à-vis the Number and Nature of Studies on Mass Media Prevention Efforts across the Globe - a Descriptive Review
}

\author{
Mesfin Awoke Bekalu, KU Leuven, Belgium \\ Steven Eggermont, KU Leuven, Belgium
}

\begin{abstract}
This paper comprehensively reviewed studies on the utilization of mass media in HIV/AIDS prevention efforts across the globe over the past ten years (2000-2010) and compared the number of studies in the different regions of the world with the regions' respective magnitude of HIV/AIDS problem. It also attempted to shed some light on the nature of the studies by classifying them based on type, objective, outcome and the type of channel they dealt with. The review showed that most of the studies on the use of mass media in HIV prevention efforts come from three of the ten UNAIDS' (2009) epidemiologic regions irrespective of the fact that the infection has increasingly become a global health threat. Most of the regions have been found to have very small, negligible number of studies that are not commensurate with the magnitude of their HIV/AIDS problem. The majority of the studies were also found to be neither formative nor summative in type and as such were not an integral part of prevention interventions. The review also revealed that studies are no longer limited to the measurement of knowledge and awareness levels of audiences and have increasingly included measures of mixed outcomes ranging from knowledge change through behaviour changes and their psychological and structural determinants. Moreover, it has been discerned that the majority of the studies reported that the uses of mass media in HIV prevention efforts across regions have been successful in varying degrees, suggesting the great potential of the mass media to enable prevention interventions achieve desired goals in places where they have been employed as campaign strategies.
\end{abstract}

Keywords: HIV/AIDS, Mass Media, Research, Prevention 


\section{Introduction}

Although HIV/AIDS has increasingly become a global health problem, different regions of the globe show varying prevalence rates of the infection (UNAIDS, 2009). No matter what their respective prevalence rates are, several countries worldwide have long started making all-out efforts to halt or at least slow down the spread of the infection in their territories. Mass media have been central in most of these efforts. The media ranging from the conventional print (newspaper, pamphlets, posters) and broadcast (radio, television) to what we now call the 'new media' have been in use to disseminate several HIV/AIDS prevention messages in a variety of intervention contexts (see Noar, 2009 for a brief review of the utility of 'old' and 'new' media as tools for HIV prevention).

The literature on mass media campaigns posits that several factors should be taken into account in order to mount and execute successful mass media health interventions. Research is one of the factors and has increasingly become important to understand and ultimately enhance the effective use of mass media in preventing several health problems including HIV/AIDS (Freimuth, Cole \& Kirby, 2000; Randolph \& Viswanath, 2004; Noar, 2009). In order for media interventions to be successful, research needs to be an integral part of the entire intervention process. In fact, research is considered to be a necessary first step of interventions and should therefore be undertaken well before a given media intervention is implemented. The demographic and psychographic characteristics of the intended audiences need to be studied in a pre-production and pre-testing research so as to determine the suitability of messages and channels (Backer, Rogers \& Sopony, 1992). Once the intervention is mounted, research in a form of process evaluation and message exposure assessment is believed to be a useful tool to make midcourse corrections and explain final outcomes (Randolph \& Viswanath, 2004). Upon the completion of the intervention, research is also important to evaluate the type and extent of effects that the media intervention yielded as well as to plan subsequent interventions if need be. Moreover, research is considered vital in explaining the interplay between interventions on the ground and the theory they are based on - given using theory has also become an important factor contributing to success.

The fact that the media have greatly changed over the past few decades and will indeed continue to change in the times to come has further increased the importance given to media research. According to Noar (2009), in this age of rapid technological changes, research 
remains to be a critical tool in order to understand the challenges as well as the opportunities that the on-going rapid changes of the media hold for HIV/AIDS prevention. Overall, given the growing potential and utility of mass media in HIV/AIDS prevention interventions, it can be gathered that research allowing us to further understand and/or enhance effective uses of mass media should be a necessary ingredient of the overall prevention efforts worldwide. Indeed, as is the case for any sort of challenge, mass media HIV/AIDS prevention challenges need to be adequately and consistently researched, solutions need to be sought, and/or new directions and opportunities have to be identified.

A close look at the HIV/AIDS literature proves that the huge potential and the widespread utility of the mass media in HIV/AIDS prevention efforts have drawn attention from the research communities across disciplines. Over the past several years, a number of studies have thus been conducted aiming at increasing understanding of mass media interventions as well as shedding light on their nature, design, delivery, effects, etc. Several authors have reviewed such studies and reported several interesting insights (e.g., Holtgrave, 1997; Myhre \& Flora, 2000; Vidanapathirana, Abramson, Forbes \& Fairley, 2005; Bertrand, O'Reilly, Denison, Anhang \& Sweat, 2006; Bertrand \& Anhang, 2006; Palmgreen, Noar \& Zimmerman, 2008; Noar, Palmgreen, Chabot, Dobransky \& Zimmerman, 2009). For instance, Myhre \& Flora (2000) have reviewed 41 articles published between 1986 and 1998 and reported the nature of the studies in terms of six components related to media campaign design and evaluation: target audience, communication channel(s), message content, campaign theme, exposure, and outcomes. In a similar review, Noar et al. (2009) have systematically reviewed and examined studies published from 1998-2007 and determined the nature of the studies based on ten dimensions of interest. Moreover, Bertrand et al (2006) have studied the effectiveness of HIV mass media campaigns in developing countries and identified the outcomes reported by the campaigns under consideration. Bertrand \& Anhang (2006) have also examined the strength of the evidence for the effects of three different types of mass media interventions - radio only, radio with supporting media, and radio and television with supporting media - on HIV/AIDS-related behaviour among young people in developing countries.

None of the previous reviews has, however, attempted to compare the number and nature of the studies in the different regions of the world with the magnitude of HIV/AIDS problem in 
the respective regions. The present review has attempted to make this comparison. More specifically, the paper attempted to comprehensively review studies on the use of mass media in HIV prevention efforts worldwide over the past ten years during which time the hope for a cure or vaccine has greatly waned and behavioural and structural interventions involving the mass media have been considered more and more useful. An attempt has then been made to compare the number of studies in the different regions of the globe with the magnitude of HIV/AIDS problem (as measured by adult prevalence rates) in the respective regions. Moreover, in addition to comparing the sheer number of studies in the different regions vis-àvis the regions' HIV/AIDS problem, an attempt has also been made to shed some light on the nature of the studies by classifying them based on type, objective, outcome and the type of channel that they dealt with.

Given the growing importance of mass media in HIV/AIDS prevention efforts worldwide and the criticality of research to understand and enhance their effective use, such comparison will help us to understand if due attention has been paid to research in the different regions to the degree that is commensurate with the magnitude of the regions' HIV/AIDS problem. The review may thus be taken as an attempt to contribute to the understanding of the role research has played in mass media HIV/AIDS prevention efforts through the depiction of the distribution and nature of the studies across the different HIV epidemiologic regions of the globe.

\section{Methods}

In order to achieve the aforementioned goals, published studies have been searched and the different epidemiologic regions of the infection have been identified. Four dimensions have also been identified for classifying the reviewed studies.

\section{Studies Searching Strategy}

Articles published over the past ten years (January 2000 - February 2010) on the use of mass media in HIV/AIDS prevention efforts have been searched from two electronic databases: Web of Science and PubMed. Several key words have been used in combination, including HIV/AIDS, mass media, mass communication, campaign, prevention, and intervention. The initial search yielded hundreds of articles which had to be further screened through a closer examination of their relevance. Thus, articles (1) that mainly dealt with HIV/AIDS 
prevention interventions and (2) reported on the utilization and/or role of mass media as a major strategy in prevention efforts have been selected. Studies that merely made mention of HIV/AIDS in studies whose major aims have been reporting efforts on, for instance, family planning, STD, use of contraceptives, abortion, and so forth have thus been excluded. Similarly, studies that simply made mention of mass media and/or any of their forms in interventions whose main strategies have been something else have been excluded. In short, the centrality of HIV/AIDS and mass media in the studies has been an important measure of relevance.

In addition to reiterated searches in the two databases, reference lists of certain key reviews (e.g. Bertrand et al., 2006; Bertrand \& Anhang, 2006; Noar et al., 2009) have also been examined to make sure that every relevant article has been included. In total, 86 studies have been found relevant for the study.

\section{Identifying Epidemiologic Regions and the Magnitude of HIV/AIDS}

Two decades ago, Piot, Curran, James, Ryder, Robert, Laga, et al. (1990) had identified three major epidemiological patterns of the HIV infection. The first pattern represented the epidemiology in North America, Europe, and Australia, where most cases of HIV infection have been limited to homosexual men and intravenous drug users and their sexual partners, the infection being largely uncommon with the rest of the population. The second pattern was the one mainly in sub-Saharan Africa and increasingly in the other parts of the world where socio-economic deprived populations live. Here HIV infection occurred through heterosexual intercourse, from mothers to infants, and through blood transfusions. The third pattern existed in the remaining regions of the world, where the virus has been introduced very lately and there have been very few cases of the infection transmitted in different ways (Piot et al., 1990:403). However, Piot et al. (1990) have been cautious enough to observe that the situation then had been far from static and indeed preferred to focus on the changing trends in their review of the global epidemiology of the infection. Elucidating the various demographic, behavioural, biological, economic and political factors that were simultaneously at work on the epidemiology of the infection, Piot et al. (1990) emphasized that the epidemiology of HIV has been becoming increasingly heterogeneous and has also been changing constantly. 
Today, almost two decades later, UNAIDS (2009) warns that HIV/AIDS continues to be a major global health problem, although important progress has been made in the fight against the epidemic in the past several years. It states that the epidemic is evolving and/or changing patterns and, hence, regions which have long been known to have the infection largely limited to drug users and homosexuals have now increasingly become characterized by heterosexual transmissions. More specifically, the epidemic in Eastern Europe and Central Asia have now increasingly become characterized by significant sexual transmission, while in regions of Asia epidemics have become increasingly characterized by significant transmission among heterosexual couples. UNAIDS (2009:9) has also made it clear that "while the rapid expansion of access to antiretroviral therapy is helping to lower AIDSrelated death rates in multiple countries and regions, it is also contributing to increases in HIV prevalence."

In its 2009 AIDS Epidemic update, UNAIDS reports the adult prevalence rates of the infection, among other things, as noted over ten epidemiologic regions of the globe. SubSaharan Africa stands out with the highest adult prevalence rate $(5.2 \%)$ followed by the Caribbean (1.0\%) and Eastern Europe \& Central Asia (0.7\%). North America and Latin America are characterized by the same rates of prevalence ( $0.6 \%$ each). Likewise, Oceania, South \& South East Asia, and Western \& Central Europe are characterized by the same rates of prevalence $(0.3 \%$ each). Middle East \& North Africa and East Asia are characterized by relatively smaller rates of prevalence $(0.2 \%$ and $0.1 \%$ respectively).

These ten different epidemiologic regions have thus been used to classify the reviewed studies and their corresponding adult prevalence rates have been used as measures of the regions' current magnitude of HIV/AIDS problems.

\section{Classifying the Studies}

In order to understand the nature of the studies, the reviewed articles have been classified based on channel, type, objective and outcome. These four dimensions have been chosen because of their presumed potential to tell about the nature of the studies.

Channel: The commonest classification of the conventional mass media as broadcast and print provides us with two sets of channels - television and radio, in one set, and print in its 
different forms in another set. In addition to these two sets, the Internet, as the 'new media', has been included to form the basis for classifying the reviewed studies based on channel.

Type: While there are several ways of categorizing research, the classification formative vs. summative has been adopted in the present study. Such types of research are normally an integral part of a given program such as mass media HIV/AIDS prevention intervention. While formative studies are conducted before and during the course of the intervention, summative studies are normally done at the end of the intervention with the main aim of evaluating outcomes. In the classification, studies that do not fit into either of the two categories have been treated as others.

Objective: Given the increasing multiplicity of the objectives of several HIV/AIDS prevention interventions worldwide (Bertrand et al., 2006), studies addressing the use of mass media in prevention efforts usually set out with a multitude of objectives - measuring audiences' awareness or knowledge about the infection, behavioural changes and/or the psychological and structural determinants of behavioural changes. The present study has therefore identified four major objective categories on which the reviewed studies can be classified. The first category included objectives related to message provision (by the media) and message exposure (of the audiences) and the resulting presence or absence of changes in awareness and/or knowledge. Category two consisted of studies dealing with and/or reporting the presence or absence of such mediating variables of behaviour change as perceptions, attitudes and beliefs. Category three included articles reporting the presence or absence of actual behaviour changes such as abstinence, limiting sexual partners, condom use, and HIV testing; and category four comprised studies reporting the presence or absence of a mixture of the above three outcomes as well as other larger social, economic and political determinants of behaviour change.

Outcome: The fourth dimension on which the reviewed studies have been categorized has been the outcome/s that they have reported. While it has been possible to categorize the studies as reporting "successful outcomes in varying degrees", "unsuccessful outcomes", and "undetermined", elucidating how successful the successful ones have been has been difficult given the weak outcome measures employed by most of the studies. This difficulty has also 
been discerned by previous reviews of HIV/AIDS campaign literature (Myhre \& Flora, 2000; Noar et al., 2009).

\section{Results}

The review identified 86 relevant peer-reviewed articles and categorized them based on UNAIDS' (2009) ten HIV/AIDS epidemiologic regions. Three studies have been found involving data from multiple countries in different regions. Geary et al. (2006) and Traquina (2007) each involved data from two different countries in two different regions and hence each has been counted twice. Similarly, Geary et al. (2008) involved data from three countries in three different regions and has thus been counted thrice. This has raised the total number of studies from 86 to 92 .

For ease of presentation, the regions have been mapped in a left-to-right descending order of HIV prevalence rates and the studies coming from each of the regions have been coded on the respective regions using the names of the authors of the studies (see Table 1). Most of the studies have come from three of the ten epidemiologic regions of UNAIDS (2009) - subSaharan Africa (40 studies), North America (27 studies) and South \& South East Asia (10 studies). While the remaining six regions have generally been characterized by very small numbers of studies, no study has been found in one of the ten epidemiologic regions - the Caribbean.

In order to determine the relationship between the number of studies in the regions and the corresponding magnitude of the regions' HIV/AIDS problem, a correlation coefficient $(r)$ has been calculated. A rather large positive correlation $(r=0.79)$ has been obtained. However, it was discerned that the result is an artificially large correlation caused by one observation with extreme values - sub-Saharan Africa. Dropping this observation (an outlier) changed what was unreasonably large correlation $(r=0.79)$ into a very small, near zero $(r=0.0463)$ correlation (see Table 2). 


\begin{tabular}{|c|c|c|c|}
\hline Traquina (2007) & \multirow[t]{2}{*}{ Table 1: Distribution of studies per region } & & \\
\hline \multicolumn{3}{|l|}{ Ybarra et al (2006) } & \\
\hline \multicolumn{4}{|l|}{ Vaughan et al (2000) } \\
\hline \multicolumn{2}{|l|}{ Tambashe et al (2003) } & \multicolumn{2}{|c|}{ Key to Acronyms: } \\
\hline \multicolumn{2}{|l|}{ Smith et al (2007) } & $\mathrm{SSA}=$ & sub-Saharan Africa \\
\hline \multirow[t]{2}{*}{ Shapiro et al (2003) } & & $\mathrm{EECA}=$ & Eastern Europe + central \\
\hline & & & Asia \\
\hline Petersen et al (2006) & & $\mathrm{NA}=$ & North America \\
\hline Peltzer \& Promtussananon & & $\mathrm{LA}=$ & Latin America \\
\hline \multicolumn{4}{|l|}{$(2003)$} \\
\hline Pappas-DeLuca et al (2008) & & Oc. $=$ & Oceania \\
\hline O’Leary et al (2007) & & $\mathrm{SSEA}=$ & South + South East Asia \\
\hline Mohammed (2001) & & $\mathrm{WCE}=$ & Western + Central Europe \\
\hline \multirow[t]{2}{*}{ Mitchell et al (2001) } & & $\mathrm{MNA}=$ & Middle East + North \\
\hline & & & Africa \\
\hline Marum et al (2008) & & $\mathrm{EA}=$ & East Asia \\
\hline Lovell et al (2007) & Zimmerman et al (2007) & & \\
\hline Lapinski \& Nwulu (2008) & Romer et al (2009) & & \\
\hline Kuhlmann et al (2008) & Roberto et al (2007) & & \\
\hline Keating et al (2006) & Reeves (2000) & & \\
\hline Katz (2006) & Pickle et al (2002) & & \\
\hline Karlyn (2001) & Olshefsky et al (2007) & & \\
\hline Hutchinson et al (2007) & $\mathrm{Ng}(2000)$ & & \\
\hline Goldstein et al (2005) & Mizuno et al (2002) & & \\
\hline
\end{tabular}




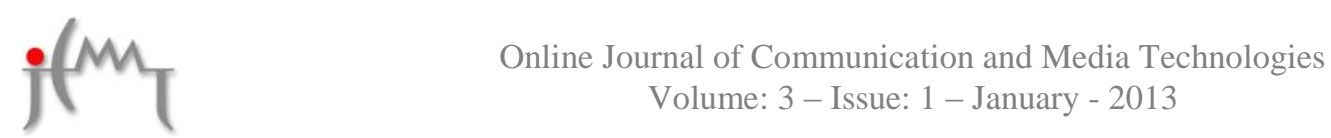

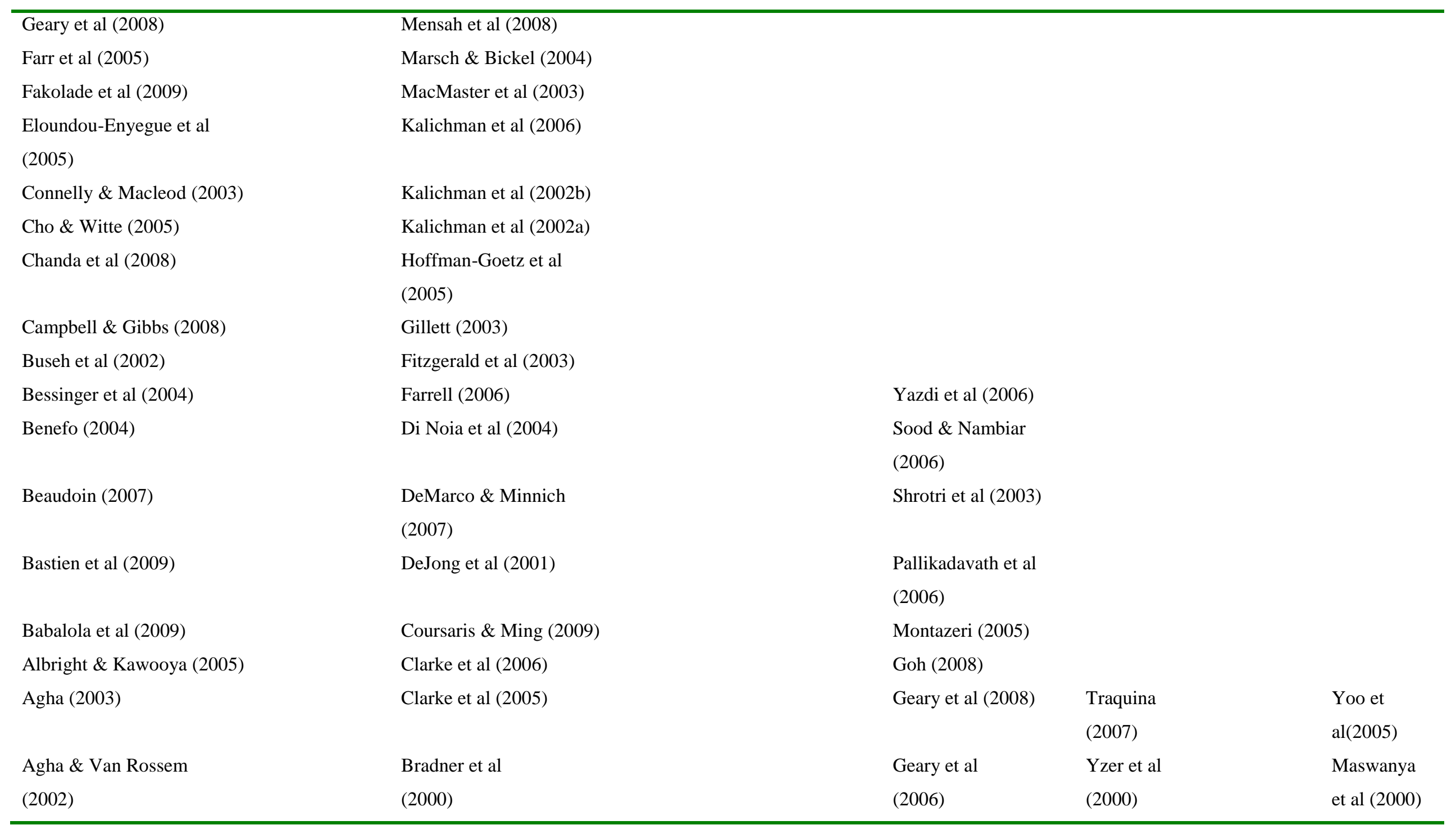




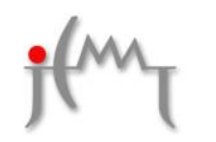

Online Journal of Communication and Media Technologies Volume: 3 - Issue: 1 - January - 2013

\begin{tabular}{|c|c|c|c|c|c|c|c|c|}
\hline $\begin{array}{l}\text { Adelore et al. } \\
\text { (2006) }\end{array}$ & & $\begin{array}{l}\text { Bhattacharya et al } \\
(2000)\end{array}$ & $\begin{array}{l}\text { Geary et al } \\
(2008)\end{array}$ & $\begin{array}{l}\text { Newman \& } \\
\text { Persson } \\
(2009)\end{array}$ & $\begin{array}{l}\text { DeSouza } \\
\text { (2007) }\end{array}$ & $\begin{array}{l}\text { Peretti-Watel } \\
\text { et al (2005) }\end{array}$ & $\begin{array}{l}\text { Hayyawi } \\
\text { et al } \\
(2010)\end{array}$ & $\begin{array}{l}\text { Li et al } \\
\text { (2009) }\end{array}$ \\
\hline $\begin{array}{l}\text { Abiodun et al. } \\
(2007)\end{array}$ & $\begin{array}{l}\text { Pinkerton et } \\
\text { al (2003) }\end{array}$ & $\begin{array}{l}\text { Benotsch et al } \\
(2004)\end{array}$ & $\begin{array}{l}\text { Geary et al } \\
(2006)\end{array}$ & $\begin{array}{l}\text { McMahon et } \\
\text { al (2004) }\end{array}$ & $\begin{array}{l}\text { DeSouza \& Dutta } \\
\text { (2008) }\end{array}$ & $\begin{array}{l}\text { McOwan et al } \\
\text { (2002) }\end{array}$ & $\begin{array}{l}\text { Al-Serouri } \\
\text { et al } \\
(2002)\end{array}$ & $\begin{array}{l}\text { Dong et al } \\
(2008)\end{array}$ \\
\hline SSA (5.2\%) & $\begin{array}{l}\text { EECA } \\
(0.7 \%)\end{array}$ & NA $(0.6 \%)$ & LA $(0.6 \%)$ & Oc. $(0.3 \%)$ & SSEA $(0.3 \%)$ & WCE $(0.3 \%)$ & $\begin{array}{l}\text { MNA(0.2 } \\
\%)\end{array}$ & EA $(0.1 \%)$ \\
\hline
\end{tabular}


Table 2: Correlation between regions' adult HIV prevalence rates and number of studies

\begin{tabular}{|c|c|c|c|c|c|}
\hline Region & Prevalence $(\mathrm{P})$ & Studies (S) & PS & $\mathrm{P}^{2}$ & $S^{2}$ \\
\hline Sub-Saharan Africa & 5.2 & 40 & 208 & 27.04 & 1600 \\
\hline Caribbean & 1.0 & 0 & 0 & 1 & 0 \\
\hline Eastern Europe & 0.7 & 1 & 0.7 & 0.49 & 1 \\
\hline \multicolumn{6}{|l|}{ +Central Asia } \\
\hline North America & 0.6 & 27 & 16.2 & 0.36 & 729 \\
\hline Latin America & 0.6 & 2 & 1.2 & 0.36 & 4 \\
\hline Oceania & 0.3 & 2 & 0.6 & 0.09 & 4 \\
\hline South + South East & 0.3 & 10 & 3 & 0.09 & 100 \\
\hline \multicolumn{6}{|l|}{ Asia } \\
\hline Western + Central & 0.3 & 4 & 1.2 & 0.09 & 16 \\
\hline \multicolumn{6}{|l|}{ Europe } \\
\hline Middle East + North & 0.2 & 2 & 0.4 & 0.04 & 4 \\
\hline \multicolumn{6}{|l|}{ Africa } \\
\hline East Asia & 0.1 & 4 & 0.4 & 0.01 & 16 \\
\hline Total & 9.3 & 92 & 231.7 & 29.57 & 2474 \\
\hline
\end{tabular}

$r=0.79$ (for the whole observations)

$r=0.0463$ (for the observations except sub-Saharan Africa, which is an outlier)

Let us now turn to the distributions of the studies per channel, type, objective, and outcome.

\section{Channel}

The reviewed studies have been classified into five based on the channel/medium they dealt with. The majority (about 37\%) of the studies have been found to be dealing with multimedia interventions, whereas a relatively large number (about 20\%) of the studies have been found focusing on the use of television. While a considerable number of studies (17.4\%) have been found to be dealing with the print media, relatively small numbers of studies (13\% each) have been found to be reporting on the uses of radio and the Internet (see Table 3).

When we see the distributions of the studies addressing the different channels across the regions, all the studies dealing with the utilization of radio and the majority (47\%) of the 
studies dealing with the use of multimedia come from sub-Saharan Africa, whereas the great majority $(83.3 \%)$ of the studies dealing with the use of the Internet and the majority (39\%) of the studies dealing with the use of television come from North America. Most of the studies dealing with the print media come from sub-Saharan Africa and North America (43.7\% and $37.5 \%$ respectively). The remaining regions, which are indeed characterized by smaller numbers of studies, featured studies dealing with either television or multimedia (see Table 3). 
Table 3: Regions, corresponding adult HIV prevalence rates, and number of studies per channel

\begin{tabular}{|c|c|c|c|c|c|c|c|c|c|c|c|c|c|}
\hline \multirow{3}{*}{ Region } & \multirow{3}{*}{$\begin{array}{c}\text { HIV } \\
\text { Prevalence } \\
(\%)\end{array}$} & \multicolumn{12}{|c|}{ Number of Studies Per Channel } \\
\hline & & \multicolumn{2}{|c|}{ TV } & \multicolumn{2}{|c|}{ Radio } & \multicolumn{2}{|c|}{ Internet } & \multicolumn{2}{|c|}{ Print } & \multicolumn{2}{|c|}{ Multimedia } & \multicolumn{2}{|c|}{ Total } \\
\hline & & $\mathrm{N}$ & $\%$ & $\mathrm{~N}$ & $\%$ & $\mathrm{~N}$ & $\%$ & $\mathrm{~N}$ & $\%$ & $\mathrm{~N}$ & $\%$ & $\mathrm{~N}$ & $\%$ \\
\hline Sub-Saharan Africa & 5.2 & 4 & 22.2 & 12 & 100 & 1 & 8.3 & 7 & 43.7 & 16 & 47 & 40 & 43.5 \\
\hline Caribbean & 1.0 & 0 & 0 & 0 & 0 & 0 & 0 & 0 & 0 & 0 & 0 & 0 & 0 \\
\hline Eastern Europe + Central Asia & 0.7 & 0 & 0 & 0 & 0 & 0 & 0 & 0 & 0 & 1 & 2.9 & 1 & 1.1 \\
\hline North America & 0.6 & 7 & 38.8 & 0 & 0 & 10 & 83.3 & 6 & 37.5 & 4 & 11.8 & 27 & 29.3 \\
\hline Latin America & 0.6 & 2 & 11.1 & 0 & 0 & 0 & 0 & 0 & 0 & 0 & 0 & 2 & 2.2 \\
\hline Oceania & 0.3 & 0 & 0 & 0 & 0 & 0 & 0 & 0 & 0 & 2 & 5.9 & 2 & 2.2 \\
\hline South + South East Asia & 0.3 & 3 & 16.6 & 0 & 0 & 1 & 8.3 & 2 & 12.5 & 4 & 11.8 & 10 & 10.9 \\
\hline Western + Central Europe & 0.3 & 0 & 0 & 0 & 0 & 0 & 0 & 1 & 6.3 & 3 & 8.8 & 4 & 4.4 \\
\hline Middle East + North Africa & 0.2 & 1 & 5.5 & 0 & 0 & 0 & 0 & 0 & 0 & 1 & 2.9 & 2 & 2.2 \\
\hline East Asia & 0.1 & 1 & 5.5 & 0 & 0 & 0 & 0 & 0 & 0 & 3 & 8.8 & 4 & 4.4 \\
\hline Total & 0.8 & 18 & 100 & 12 & 100 & 12 & 100 & 16 & 100 & 34 & 100 & 92 & 100 \\
\hline
\end{tabular}




\section{Type}

The reviewed studies have also been classified into three based on type: formative, summative and others. Consequently, while only a token $(7.6 \%)$ of the studies have been found to be formative, $41.3 \%$ of them have been found to be summative. The majority $(51 \%)$ of the studies have been found to be under the category others as they could not fit into either of the formative-summative categories. The formative-summative ratio has been found to be roughly the same across the regions; that is, formative studies tended to be very few compared to the summative ones across the regions. Compared to formative and summative types of studies, those under the category others have been found to be the largest proportion of studies conducted in most of the regions except sub-Saharan Africa where summative studies outnumbered the other two types (see Table 4). 
Table 4: Regions, corresponding adult HIV prevalence rates, and number of studies per type

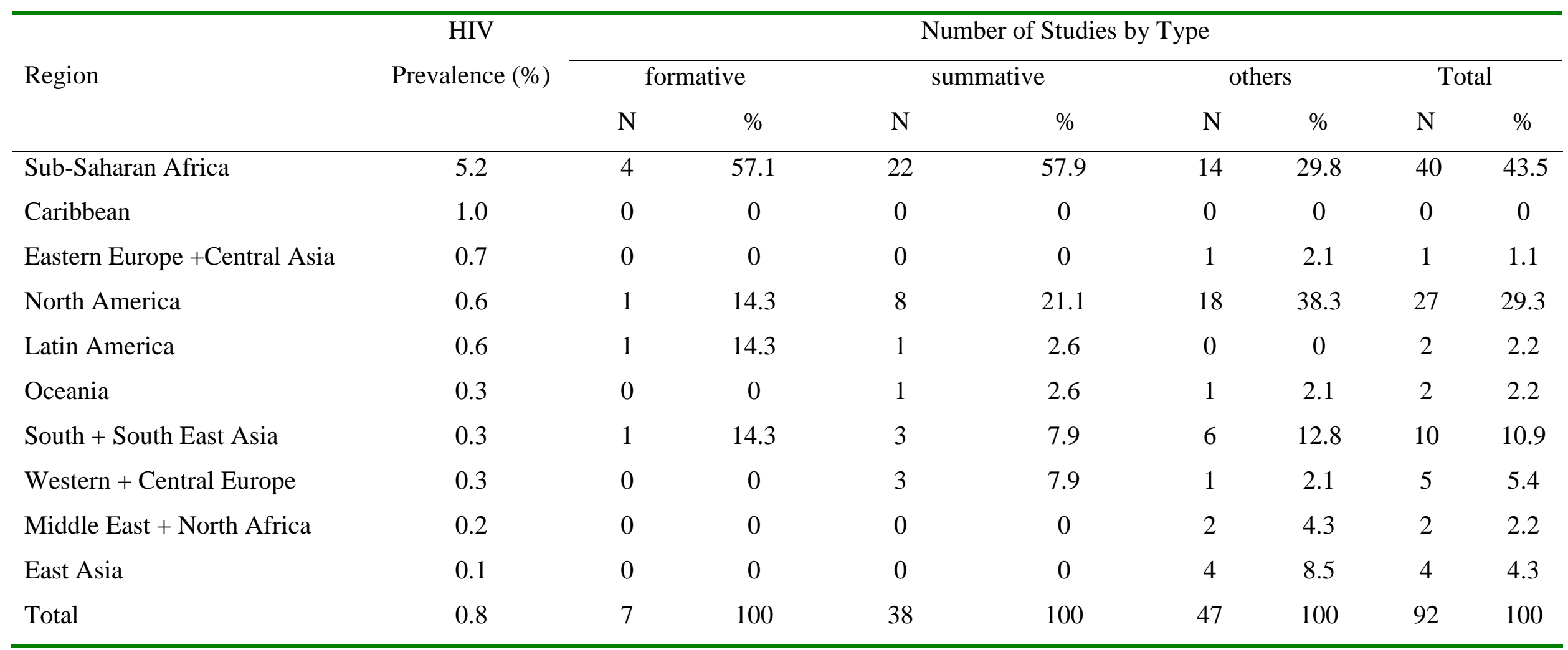




\section{Objective}

The third dimension on which the reviewed studies classified has been the objectives they set for themselves. Four objective categories have been identified. The majority (50\%) of the studies have had multiple objectives: dealing with and/or reporting mixed outcomes ranging from knowledge change through behaviour changes and their psychological and structural determinants. A considerable number (32.6\%) of the studies had also the objective of reporting outcomes related to the presence or absence of such mediating variables/predictors of behaviour change as perceptions, attitudes and beliefs. While a relatively small number of studies have been found to be dealing with and/or reporting the impacts of mass media on actual behaviour changes, a rather small number of studies have been found to be dealing with and/or reporting the informative roles of the media and the subsequent presence or absence of awareness and/or knowledge changes on the part of the audience (see Table 4). Moreover, when we see the knowledge - mediating variables - actual behaviour - mixed proportions of the studies, we do not see any pattern of increase or decrease across the different epidemiologic regions (see Table 5). 
Table 5: Regions, corresponding adult HIV prevalence rates, and number of studies per objective

\begin{tabular}{|c|c|c|c|c|c|c|c|c|c|c|c|}
\hline \multirow{4}{*}{ Region } & \multirow{4}{*}{$\begin{array}{c}\text { HIV } \\
\text { Prevalence }(\%)\end{array}$} & \multicolumn{10}{|c|}{ Number of studies by objective categories } \\
\hline & & \multirow{2}{*}{\multicolumn{2}{|c|}{$\begin{array}{c}\text { knowledge/awaren } \\
\text { ess }\end{array}$}} & \multirow{2}{*}{\multicolumn{2}{|c|}{$\begin{array}{l}\text { mediating } \\
\text { variables }\end{array}$}} & \multicolumn{2}{|c|}{ actual behaviour } & \multirow{2}{*}{\multicolumn{2}{|c|}{ mixed and beyond }} & \multirow{2}{*}{\multicolumn{2}{|c|}{ Total }} \\
\hline & & & & & & & & & & & \\
\hline & & $\mathrm{N}$ & $\%$ & $\mathrm{~N}$ & $\%$ & $\mathrm{~N}$ & $\%$ & $\mathrm{~N}$ & $\%$ & $\mathrm{~N}$ & $\%$ \\
\hline Sub-Saharan Africa & 5.2 & 2 & 28.6 & 20 & 66.7 & 6 & 66.7 & 12 & 26.1 & 40 & 43.5 \\
\hline Caribbean & 1.0 & 0 & 0 & 0 & 0 & 0 & 0 & 0 & 0 & 0 & 0 \\
\hline Eastern Europe + Central Asia & 0.7 & 0 & 0 & 0 & 0 & 0 & 0 & 1 & 2.2 & 1 & 1.1 \\
\hline North America & 0.6 & 4 & 57.1 & 4 & 13.3 & 1 & 11.1 & 18 & 39.1 & 27 & 29.3 \\
\hline Latin America & 0.6 & 0 & 0 & 2 & 6.7 & 0 & 0 & 0 & 0 & 2 & 2.2 \\
\hline Oceania & 0.3 & 0 & 0 & 0 & 0 & 1 & 11.1 & 1 & 2.2 & 2 & 2.2 \\
\hline South + South East Asia & 0.3 & 1 & 14.3 & 2 & 6.7 & 0 & 0 & 7 & 15.2 & 10 & 10.9 \\
\hline Western + Central Europe & 0.3 & 0 & 0 & 1 & 3.3 & 1 & 11.1 & 2 & 4.3 & 4 & 4.3 \\
\hline Middle East + North Africa & 0.2 & 0 & 0 & 0 & 0 & 0 & 0 & 2 & 4.3 & 2 & 2.2 \\
\hline East Asia & 0.1 & 0 & 0 & 1 & 3.3 & 0 & 0 & 3 & 6.5 & 4 & 4.3 \\
\hline Total & 0.8 & 7 & 100 & 30 & 100 & 9 & 100 & 46 & 100 & 92 & 100 \\
\hline
\end{tabular}




\section{Outcome}

The fourth dimension on which the reviewed studies classified has been the outcomes they reported. They have been classified into three based on this dimension: successful in varying degrees, unsuccessful and undetermined. The majority (73.9\%) of the studies have been found to be reporting that the uses of mass media in HIV prevention interventions across regions have been successful in varying degrees; though elucidating the degree of success remained difficult. Whereas about $16.3 \%$ of the studies have not determined the outcomes in clear terms and/or did not say anything about outcomes, only $9.8 \%$ of the studies were found to be reporting negative and/or unsuccessful results of the utilization of mass media in prevention efforts. The successful-unsuccessful-undetermined ratio appears to be roughly the same across the regions with the exception of North America and Eastern Europe \& Central Asia; that is, the number of studies reporting successful outcomes tends to be the highest while the number of studies with undetermined outcomes tends to be the lowest across the regions. However, while the region Eastern Europe \& Central Asia has its only study under the unsuccessful category, North America featured more studies with undetermined outcomes than unsuccessful ones (see Table 6). 
Table 6: Regions, corresponding adult HIV prevalence rates, and number of studies per outcome

\begin{tabular}{|c|c|c|c|c|c|c|c|c|c|}
\hline \multirow{3}{*}{ Region } & \multirow{3}{*}{$\begin{array}{c}\text { HIV } \\
\text { prevalence } \\
(\%)\end{array}$} & \multicolumn{8}{|c|}{ Number of Studies by outcomes } \\
\hline & & \multicolumn{2}{|c|}{$\begin{array}{c}\text { successful in } \\
\text { varying } \\
\text { degrees }\end{array}$} & \multicolumn{2}{|c|}{$\begin{array}{c}\text { Negative/ } \\
\text { unsuccessful }\end{array}$} & \multicolumn{2}{|c|}{ undetermined } & \multicolumn{2}{|c|}{ Total } \\
\hline & & $\mathrm{N}$ & $\%$ & $\mathrm{~N}$ & $\%$ & $\mathrm{~N}$ & $\%$ & $\mathrm{~N}$ & $\%$ \\
\hline Sub-Saharan & 5.2 & 34 & 50 & 4 & 44.4 & 2 & 13.3 & 40 & 43.5 \\
\hline \multicolumn{10}{|l|}{ Africa } \\
\hline Caribbean & 1.0 & 0 & 0 & 0 & 0 & 0 & 0 & 0 & 0 \\
\hline Eastern Europe & 0.7 & 0 & 0 & 1 & 11.1 & 0 & 0 & 1 & 1.1 \\
\hline \multicolumn{10}{|l|}{ +Central Asia } \\
\hline North America & 0.6 & 15 & 22.1 & 2 & 22.2 & 10 & 66.7 & 27 & 29.3 \\
\hline Latin America & 0.6 & 2 & 2.9 & 0 & 0 & 0 & 0 & 2 & 2.2 \\
\hline Oceania & 0.3 & 1 & 1.5 & 0 & 0 & 1 & 6.7 & 2 & 2.2 \\
\hline South + South & 0.3 & 8 & 11.8 & 1 & 11.1 & 1 & 6.7 & 10 & 10.9 \\
\hline \multicolumn{10}{|l|}{ East Asia } \\
\hline Western + & 0.3 & 3 & 4.4 & 0 & 0 & 1 & 6.7 & 4 & 4.4 \\
\hline \multicolumn{10}{|l|}{ Central Europe } \\
\hline Middle East + & 0.2 & 2 & 2.9 & 0 & 0 & 0 & 0 & 2 & 2.2 \\
\hline \multicolumn{10}{|l|}{ North Africa } \\
\hline East Asia & 0.1 & 3 & 4.4 & 1 & 11.1 & 0 & 0 & 4 & 4.4 \\
\hline Total & 0.8 & 68 & 100 & 9 & 100 & 15 & 100 & 92 & 100 \\
\hline
\end{tabular}




\section{Discussion}

The results of the review indicated that most of the studies on the use of mass media in HIV/AIDS prevention efforts come from three of the ten UNAIDS' (2009) epidemiologic regions irrespective of the fact that the infection has increasingly become a global health threat. While sub-Saharan Africa, North America and South \& South East Asia have each considerable numbers of studies, the remaining seven regions have been found to be characterized by no or very small numbers of studies.

It has been observed that the number of studies coming from sub-Saharan Africa has been on the increase over the past decade. The 1986-1998 comprehensive review of Myhre \& Flora (2000) revealed that there were no studies - fulfilling their selection criteria - in Africa (except Uganda and Zambia), whereas this has changed in Noar et al.'s (2009) subsequent review (1998-2007) with half (17/34) of the reviewed articles coming from Africa. This increasing trend has also been discerned in the present review; the majority of the studies reviewed in this paper come from sub-Saharan Africa. This appears to be due to the fact that the infection has thus far been rifer in this region than in others, and as such it seems that the problem has drawn considerable attention from the research community in the region. In fact, the problem of HIV/AIDS in this region appears to have drawn the attention of researchers even from outside the region as a look at the institutional affiliations of some of the authors of the studies in this region witnesses. The relative amount of attention in a form of research on HIV/AIDS mass media campaigns given to the problem of HIV/AIDS in sub-Saharan Africa appears to be commensurate with the magnitude of the problem in the region. However, the rather high prevalence rate of the infection in the region $(5.2 \%)$ appears to be in need of more and continued efforts to enhance the effective use of mass media in the fight against the pandemic.

It has been discerned that North America ranked second in the number of studies whereas it ranked fourth in HIV prevalence rate. In other words, the studies in this epidemiologic region outnumbered the studies in the second and third regions with regard to HIV prevalence rate, implying that relatively better efforts have been made to address the effective use of mass media in North America than in the Caribbean and Eastern Europe \& Central Asia where no and only one study, respectively, has been found. South \& South East Asia ranked third in the number of studies while it was the seventh epidemiologic region in HIV prevalence rate. As such, this region outnumbered in studies all the four regions up in HIV prevalence rate except 
sub-Saharan Africa and North America. The remaining regions have generally been characterized by very small, negligible number of studies that do not have any clear patterned relationship with the magnitude of their HIV problem.

Overall, when we compare the number of studies in the regions with their HIV prevalence rates, we see a very small, near zero correlation $(r=0.0463)$, except for sub-Saharan Africa where both the prevalence rate of the pandemic and the number of studies are relatively higher than those in the rest of the regions. The reasons for the lack of studies that are proportional to the problem of HIV/AIDS in most of the regions could be different. One could be the small number or absence of mass media campaigns on HIV/AIDS in the regions. Another could be the absence or lack of attention for the issue from the respective academic disciplines, or the absence or lack of resources and expertise to conduct such studies. Whatever reasons there might be, however, given the increasing global nature of the infection and the centrality of research-based mass media interventions in the fight against the infection, the extremely small numbers of studies in general and the absence of such efforts to the degree that is commensurate with the magnitude of the problem in some of the regions in particular appear to be worthy of attention.

Through the classification of the reviewed studies based on channel, type, objective, and outcome, certain salient issues have also become evident.

Channel: As in Myhre \& Flora (2000) and Noar et al. (2009), most of the reviewed studies have been found to be dealing with multichannel interventions suggesting that interventions have now increasingly become multichannel instead of relying on single channels. Those addressing the use of television are next to multimedia. Seemingly due to the fact that television is the most popular medium in North America, the majority of the studies addressing the use of this medium came from this epidemiologic region. All the reviewed studies addressing the use of radio came from sub-Saharan Africa in line with the findings of several studies reporting the popularity and accessibility of the medium as the chief source of information about the infection for most people living in developing nations where the pandemic has a strong hold (e.g., Juma, 2001; Benefo, 2004; Albright \& Kawooya, 2005; Bastien, Leshabari, \& Klepp, 2009). Almost all the reviewed studies addressing the use of the Internet are found to be conducted in North America seemingly in line with the relatively higher popularity and accessibility of the medium in the region. Most of the reviewed studies 
on the use of the print media came from North America and sub-Saharan Africa. Overall, the distribution of the studies addressing the different medium across the ten epidemiologic regions appears to be responsive more to the popularity and accessibility of the medium in the respective regions than the magnitude of the regions' HIV problem. Put in other words, the choice of medium to focus on did not seem to have any relation with the magnitude of the region's HIV problem, and instead appeared to be influenced by the relative popularity and accessibility of the medium in the regions.

Type: The classification formative vs. summative has been used in the present study owing to the fact that such types of research are usually considered to be an integral part of a given program such as mass media HIV/AIDS prevention intervention. It has been argued that during planning and while in operation, utilizing pretesting and formative evaluation techniques helps to appraise and improve communication campaigns and contributes to effectiveness (Backer et al., 1992; Noar, 2006). Formative research enables "campaign planners to truly understand their target audience in terms of the problem behaviour at hand, their message preferences, and the most promising channels through which they can be reached" (Noar, 2006:24). Once the communication intervention has been completed, an evaluation in a form of summative research is also necessary so as to come to grips with the results of the intervention and plan subsequent interventions if need be. Given their much acclaimed contribution to campaign effectiveness, the campaign literature has seen that these types of research - formative and summative - have increasingly become an integral part of prevention interventions. The present study has, however, found that most of the studies conducted on the use of mass media in HIV prevention efforts are neither formative nor summative in type. Those grouped under others were found to be the majority of the studies as a whole and were also found to be the largest proportion of the formative-summativeothers ratio in all the regions except sub-Saharan Africa. It has been observed that formative studies were tokenistic despite their much acclaimed advantages. There have been indeed more summative studies than formative ones. But, while summative research is vital to evaluate the end results or outcomes of an intervention, such a study would not redeem an intervention from failure as the formative one might do.

The fact that the majority of the reviewed studies have been found to be neither formative nor summative appears to be worthy of attention here. The majority of the studies were more of academic than applied in nature. These studies were not focused on a particular 
intervention(s), and instead addressed such issues as the relationships between source of information and/or exposure to the mass media on the one hand, and levels of knowledge, kinds of beliefs, attitudes, behaviours and so forth on the other hand, as well as portrayals and representations of the infection and/or the people with the infection on the one hand, and their likely impacts on prevention efforts on the other hand. While such studies may have the potential to increase our understandings of the interplay between mass media and HIV/AIDSrelated knowledge and/or behaviour change in general, and may ultimately contribute to the pool of the field's knowledge, their immediate significance to interventions remains debatable when compared with the formative-summative types of studies.

While there may be several reasons to dictate the type of studies to be the way they are, the relatively small number of formative studies worldwide, and the sheer absence of such studies in some of the regions imply the marginal role research is playing in assisting mass media prevention interventions achieve their goals of fighting the spread of the pandemic. Indeed, the fact that the majority of the reviewed studies have been found to be neither formative nor summative suggests that research has not truly been an integral part of mass media prevention interventions in most of the regions of the globe.

Objective: The majority of the studies reviewed in this paper have had multiple objectives. With regard to this dimension, the findings of this study appear to be in agreement with Noar et al. (2009); that is, studies are no longer limited to the measurement of knowledge and awareness levels of audiences and have increasingly included measures of the psychological determinants of behaviour change and actual behaviour change to an appreciable degree. The relatively large number of studies dealing with the psychological determinants of behaviour change added to those measuring actual behaviour changes, when balanced against the number of studies dealing with the mere informative power of the media, shows the increasing trend of studies purporting to measure behaviour and behaviour related outcomes. This trend appears to be justifiable as awareness and knowledge issues would not be the preoccupations of several intervention contexts given the number of years the world has been into the epidemic. Moreover, in line with Bertrand et al. (2006), the increasing trend of studies addressing not only awareness and behavioural issues but also the larger social, economic and political determinants of behaviour change has been gathered in the present study. 
Outcome: Encouraging results have been discerned in this review with regard to the outcomes that studies on the utility of mass media in HIV prevention have reported. While the majority of the studies reported that the uses of mass media have been successful in varying degrees, only a token reported negative outcomes or failures. Indeed, as most of the studies have been neither formative nor summative evaluations in type, there have been more studies that neither determined the successfulness of the studies nor reported any outcomes of failure or success than those reporting failures. When we see the proportions of successfulunsuccessful-undetermined studies across the regions, we notice a left-to-right decreasing pattern except two of the regions - North America which has been characterized by more undetermined studies than unsuccessful ones, and Eastern Europe \& Central Asia which has its only study under the unsuccessful category. Overall, the fact that most of the reviewed studies reported successful outcomes in varying degrees suggests the great potential of the mass media to enable prevention interventions achieve desired results in areas where they have been used as campaign strategies. Nevertheless, while these findings are congruent with the growing literature abounding in evidence for the effectiveness of the mass media in health interventions, we need to be cautious that the so-called publication bias may have also been at work and somehow coloured the findings.

\section{Limitation}

This review has one major limitation related to publication language. All the studies searched and reviewed here have been the ones published in English. While most standard publications are multilingual and hence have an English version of their articles or at least their abstracts, it is conceivable that there may be certain other non-English monolingual studies across the globe which may have been ignored in this comprehensive review. 


\section{References}

Abiodun, M. O., Ijaiya, M. A., Aboyeji, P. A. (2007) Awareness and knowledge of motherto-child-transmission of HIV among pregnant women. Journal of the National Medical Association, 99(7), 758-763.

Adelore, O. O. (2006) Impact of HIV/AIDS Prevention Promotion Programmes on Behavioural Patterns among Rural Dwellers in South Western Nigeria. Journal of Human Ecology, 20(1)

Agha, S. (2003) The impact of a mass media campaign on personal risk perception, perceived self-efficacy and on other behavioural predictors. AIDS Care, 15(6), 749-762.

Agha, S. \& Van Rossem, R. (2002) Impact of mass media campaigns on intentions to use the female condom in Tanzania. International Family Planning Perspectives, 28(3), 151-158.

Albright, K. \& Kawooya, D. (2005) The Role of Information in Uganda's Reduction of HIV/AIDS: individual perceptions of HIV/AIDS information. Information Development, 21(2).

Al-Serouri A.W., Takioldin M., Oshish H., Aldobaibi A., \& Abdelmajed A. (2002). Knowledge, attitudes and beliefs about HIV/AIDS in Sana'a, Yemen. East Mediterranean Health Journal, 8(6), 706-15.

Babalola, S., A. Fatusi \& J. Anyanti (2009) Media saturation, communication exposure and HIV stigma in Nigeria. Social Science and Medicine, 68(8).

Backer, T.E., Rogers, E.M. \& Sopony, P (1992) Designing Health Communication Campaigns: What Works? London: SAGE

Bankole, A., Singh, S., Hussain, R., \& Oestreicher, G. (2009) Condom Use for Preventing STI/HIV and Unintended Pregnancy Among Young Men in Sub-Saharan Africa. American Journal of Men's Health, 3(1), 60-78.

Bastien, S., Leshabari, M.T., \& Klepp, K. (2009) Exposure to information and communication about HIV/AIDS and perceived credibility of information sources among young people in northern Tanzania. African Journal of AIDS Research, 8(2), 213-222.

Beaudoin, C.E. (2007) HIV prevention in sub-Saharan Africa: a multilevel analysis of message frames and their social determinants. Health Promotion International, 22(3), 198-206.

Benefo, K.D. (2004) The Mass Media and HIV/AIDS Prevention in Ghana. Journal of Health and Population in Developing Countries, (ISSN 1095-8940) 
Benotsch, E.G., Kalichman, S., \& Weinhardt, L.S. (2004) HIV-AIDS patients' evaluation of health information on the Internet: The digital divide and vulnerability to fraudulent claims. Journal of consulting and clinical psychology, 72(6).

Bertrand, J. T., O’Reilly, K., Denison, J., Anhang, R. \& Sweat, M. (2006) Systematic review of the effectiveness of mass communication programs to change HIV/AIDS-related behaviours in developing countries. Health Education Research: Theory and Practice. 21(4), 567-597

Bertrand, J.T. \& Anhang, R. (2006) The effectiveness of mass media in changing HIV/AIDSrelated behaviour among young people in developing countries. World Health Organization Technical Report Series. 938. 317-341.

Bhattacharya, G., Cleland, C., \& Holland, S. (2000) Knowledge about HIV/AIDS, the perceived risks of infection and sources of information of Asian-Indian adolescents born in the USA. AIDS Care, 12(2), 203-209

Bradner, C.H., Ku, L. \& Lindberg, L.D. (2000) Older, but not wiser: how men get information about AIDS and sexually transmitted diseases after high school. Family Planning Perspectives, 32(1), 33-38.

Buseh, A.G., Glass, L.K., McElmurry, B.J., Mkhabela, M., Sukati, N.A. (2002) Primary and preferred sources for HIV/AIDS and sexual risk behavior information among adolescents in Swaziland, Southern Africa. International Journal of Nursing Studies, $39(5), 525-538$.

Campbell, C. \& Gibbs, A. (2008) Representations of HIV/AIDS Management in South African Newspapers. African Journal of AIDS Research, 7(2), 195-208.

Chanda, M., Mchombu, K. \& Nengomasha, C. (2008) The Representation of HIV/AIDS in the Media and its Impact among Young People in Namibia: a study of Windhoek and Katima Mulilo. Information Development, 24(3).

Clarke, J.N. McLellan, L. \& Hoffman-Goetz, L. (2006) The Portrayal of HIV/AIDS in two Popular African American Magazines. Journal of Health Communication, Vol. 11, pp. 495-507.

Clarke J.N., Friedman D.B., Hoffman-Goetz L. (2005) Canadian Aboriginal people's experiences with HIV/AIDS as portrayed in selected English language Aboriginal media (1996-2000). Social Science \& Medicine, 60(10), 2169-2180

Connelly, M. \& Macleod, C. (2003) Waging war: discourses of HIV/AIDS in South African media. African Journal of AIDS Research, Vol. 2, No.1, pp. 63-73. 
Coursaris, C.K., \& Ming, L. (2009) An analysis of social support exchanges in online HIV/AIDS self-help groups. Computer in Human Behaviour, 25(4), 911-918

Dejong, W., Wolf, R.C., Austin, S.B. (2001) U.S. Federally Funded Television Public Service Announcements (PSAs) to Prevent HIV/AIDS: A Content Analysis, Journal of Health Communication. Vol. 6, pp.249-263

DeMarco, R.F. \& Minnich, C.A. (2007) Men's experiences viewing an HIV/AIDS prevention education film by and for women. American Journal of Men's Health, 1(3), 183-189.

De Souza, R. \& Dutta, M.J. (2008) Global and Local Networking for HIV/AIDS Prevention: The Case of the Saathii e-Forum. Journal of Health Communication, Vol. 13, 326344

De Souza, R. (2007) The Construction of HIV/AIDS in Indian Newspapers: a frame analysis. Health Communication. Vol. 21, No. 3, pp. 257-266.

Di Noia J., Schinke S.P., Pena J.B., Schwinn T.M. (2004) Evaluation of a brief computermediated intervention to reduce HIV risk among early adolescent females. The Journal of Adolescent Health, 35(1), 62-4.

Dong, D. T. Chang \& Chen, D. (2008) Reporting AIDS and the Invisible Victims in China: Official Knowledge as News in the People's Daily, 1986-2002. Journal of Health Communication, Vol. 13, pp. 357-374.

Eloundou-Enyegu, P.M., Meekers, D., Calves, A.E. (2005) From awareness to adoption: The effect of aids education and condom social marketing on condom use in Tanzania (1993-1996). Journal of Biosocial Science, 37(3), 257-268.

Fakolade, R., Adebayo, S. B., Anyanti, J., \& Ankomah, A. (2009) The Impact Of Exposure To Mass Media Campaigns And Social Support On Levels And Trends Of HIVRelated Stigma And Discrimination In Nigeria: Tools For Enhancing Effective HIV Prevention Programmes. Journal of Biosocial Science, Vol. 17, 1-13.

Farr, A. C., Witte, K., Jarato, K., \& Menard, T. (2005) The Effectiveness of Media Use in Health Education: Evaluation of an HIV/AIDS Radio Campaign in Ethiopia, Journal of Health Communication. Vol. 10, pp. 225-235

Farrel, K. P. (2006) HIV on TV: Conversations with Young Gay Men. Sexualities, 9(2), 193213

Fitzgerald, K. Chakraborty, J., Shah, T., Khuder, S. \& Duggan, J. (2003) HIV/AIDS Knowledge among Female Migrant Farm Workers in the Midwest. Journal of Immigrant Health, Vol. 5, No. 1 
Fordham, G. (2005) A New Look at Thai AIDS: Perspectives from the Margin. Vol. 4. Canada: Berghahn Books.

Freimuth, V., Cole, G. \& Kirby, S. (2000) 'Issues in Evaluating Mass Media-Based Health Communication Campaigns', a WHO Monograph.

Geary, C. W., McClain, B.H., Neupane, S., Castelnau, L., Brown, J.D. (2006) Does MTV reach an appropriate audience for HIV prevention messages? Evidence from MTV viewership data in Nepal and Brazil. Journal of Health Communication, Vol. 11, No. 7, pp. 665-681

Geary, C. W., Burke, H.M., Johnson, L., Liku, J., Castelnau, L., Neupane, S., \& Niang, C. 2008. Personal Involvement of Young People in HIV Prevention Campaign Messages: The Role of Message Format, Culture, and Gender. Health Education and Behaviour, 35(2), 190-206

Gillett, J. (2003) Media activism and Internet use by people with HIV/AIDS. Sociology of Health and Illness, 25(6).

Goh, G. (2008) It's the Gays' Fault: News and HIV as Weapons Against Homosexuality. Journal of communication Inquiry, 32(4), 383-399.

Goldstein, S., Usdin, S., Scheepers, E., Japhet, G. (2005) Communicating HIV and AIDS, What Works? A Report on the Impact Evaluation of Soul City's Fourth Series. Journal of Health Communication, Vol. 10, pp. 465-483.

Hayyawi, A.H., Al-Marayaty, A.Y., Salman, W.S., and Hamed, W. (2010) HIV/AIDS knowledge, attitudes and beliefs among a group of Iraqis. Eastern Mediterranean Health Journal, 16(1), 18-23.

Hoffman-Goetz, L., Friedman, D.B. \& Clarke, J.N. (2005) HIV/AIDS Risk Factors as Portrayed in Mass Media Targeting First Nations, Métis and Inuit Peoples of Canada. Journal of Health Communication, Vol. 10, pp. 145-162.

Holtgrave, D.R. (1997) Public Health Communication Strategies for HIV prevention: past and emerging roles. AIDS, 11 (Suppl. A) S183-S190.

Hutchinson, P.L., Mahlalela, X. \& Yukich, J. (2007) Mass Media, Stigma, and Disclosure of HIV Test Results: Multilevel Analysis in the Eastern Cape, South Africa. AIDS Education and Prevention, 19(6) 489-510.

Johnny, L. \& Mitchell, C. (2006) 'Live and Let Live': An Analysis of HIV/AIDS-Related Stigma and Discrimination in International Campaign Posters. Journal of Health Communication, Vol. 11, pp. 755-767. 
Juma, M.N. (2001) Coping with HIV/AIDS in Education: case studies of Kenya and Tanzania. London: Commonwealth Secretariat.

Kalichman, S.C., Weinhardt, L., Benotsch, E., DiFonza, K., Luke, W., \& Austin, J. (2002a) Internet access and Internet use for health information among people living with HIV-AIDS. Patient Education and Counselling, 46(2), 109-116.

Kalichman, S.C., Weinhardt, L., Benotsch, E., \& Cherry, C. (2002b) Closing the digital divide in HIV/AIDS care: development of a theory-based intervention to increase Internet access. AIDS Care, 14(4). 523-537.

Kalichman, S.C., Cherry, C., Cain, D., Pope, H., Kalichman, M., Eaton, L. et al (2006) Internet-based health information consumer skills intervention for people living with HIV/AIDS. Journal of Consulting and Clinical Psychology, 74(3), 545-554.

Karlyn, A.S. (2001) The impact of a targeted radio campaign to prevent STIs and HIV/AIDS in Mozambique. AIDS Education and Prevention, Vol. 13, No. 5, pp. 438-451

Katz, I. (2006) Explaining the increase in condom use among South African young females. Journal of Health Communication, 11(8), 737-753.

Keating, J., Meekers D., and Adewuyi, A. (2006) Assessing effects of a media campaign on HIV/AIDS awareness and prevention in Nigeria: results from the VISION Project. BMC Public Health, 6(123).

Kuhlmann, A.K.S. J. M. Kraft, C. Galavotti, T. L. Creek, M. Mooki and R. Ntumy (2008) Radio role models for the prevention of mother-to-child transmission of HIV and HIV testing among pregnant women in Botswana. Health Promotion International, 23(3).

Lapinski, M.K. and Nwulu, P. (2008) Can a short film impact HIV-related risk and stigma perceptions? Results from an experiment in Abuja, Nigeria. Health Communication, 23(5), 403-412.

Lapinski, M.K., Randall, L.M., Peterson, M., Peterson, A., and Klein, K. (2009) Prevention Options for Positives: The Effects of a Health Communication Intervention for Men Who Have Sex with Men Living With HIV/AIDS. Health Communication, 24, $562-$ 571.

Li, L., Rotheram-Borus, M.J., Yao, L., Zunyou, W., Chunqing, L., and Jihui, G. (2009) Mass Media and HIV/AIDS in China, Journal of Health Communication. Vol. 14, No. 5, pp. 424-438.

Lovell C.C., Pappas-Deluca K.A., Sebert Kuhlmann A.K, Koppenhaver T., Kong S., Mooki M., Galavotti C. (2007-2008) "One day I might find myself HIV-positive like her": 
audience involvement and identification with role models in an entertainmenteducation radio drama in Botswana. International Quarterly of Community Health Education, 28(3), 181-200.

MaCmaster, S.A., Aquino, R., Vail, K.A. (2003) Providing HIV education and outreach via Internet chat rooms to men who have sex with men. Journal of human behaviour in the social environment, 8(2-3), 145-151

Marsch, L.A. \& Bickel, W.K. (2004) American Journal of Health Behaviour, 28(4), 316-327.

Marum, E., Morgan, G., Hightower, A., Ngare, C. \& Taegtmeyer, M. (2008) Using mass media campaigns to promote voluntary counselling and HIV-testing services in Kenya. AIDS, 22(15).

Maswanya E., Moji K., Aoyagi K., Yahata Y., Kusano Y., Nagata K. et al (2000) Knowledge and attitudes toward AIDS among female college students in Nagasaki, Japan. Health Education Research, 15(1), 5-11.

McMahon, T., Fairley, C.K., Donovan, B., Wan, L. and Quin, J. (2004) Evaluation of an ethnic media campaign on patterns of HIV testing among people from culturally and linguistically diverse backgrounds in Australia. Sexual Health, 1(2), 91-4.

McOwan, A., Gilleece, Y., Chislett, L., \& Mandalia, S. (2002). Can targeted HIV testing campaigns alter health-seeking behaviour? AIDS Care, 14, 385-390.

Mensah M.N., Waugh T., Lavoie R., Dumas J., Bernier M., Garneau M.J., Giroux C., Otis J. (2008) "The VIHsibilite Project": HIV-positive people in the Quebec press and community responses. AIDS Care, 20(5), 596-600.

Mitchell, K., Nakamanya, S., Kamali, A., Whitworth, J.A. (2001) Community-based HIV/AIDS education in rural Uganda: which channel is most effective? Health Education Research, 16(4), 411-23.

Mizuno, Y., Kennedy, M., Weeks-Norton, K., Myllyluoma, J. (2002) An examination of adolescents who were and were not exposed to "Teens Stopping AIDS": reaching the hard-to-reach. Journal of Health Communication, 7(3), 197-203.

Mohammed, S. (2001) Personal communication networks and the effects of an entertainmenteducation radio soap opera in Tanzania Journal of Health Communication, 6(2), $137-154$

Montazeri, A. (2005) AIDS knowledge and attitudes in Iran: results from a population-based survey in Tehran. Patient Education and Counselling, 57(2), 199-203.

Morisky, D. E. \& Coan, D. L. (1998) Asia: the new epidemic zone for HIV/AIDS. Journal of Health Communication, Vol. 3, pp. 185-191 
Myhre, S.L. \& Flora, J.A. (2000) HIV/AIDS Communication Campaigns: Progress and Prospects. Journal of Health Communication, Vol. 5, (supplement) 29-45

Newman, C. \& Persson, A. (2009) Fear, complacency and the spectacle of risk: the making of HIV as a public concern in Australia, Health, 13(1), 7-2.

Ng, H. (2000) AIDS in the media. Harvard AIDS Review. 2000. Winter. 18-20.

Noar, S.M., Palmgreen, P., Chabot, M., Dobransky, N., \& Zimmerman, R.S. (2009) A TenYear Systematic Review of HIV/AIDS Mass Communication Campaigns: Have we made progress? Journal of Health Communication, Vol.14, pp. 15-42

Noar, S.M., Black, H.G., Pierce, L.B. (2009) Efficacy of computer technology-based HIV prevention interventions: a meta-analysis. AIDS, 23(1), 107-115.

Noar, S.M. (2009) The Utility of "Old" and "New" media as Tools for HIV prevention. In Pope, C., White, R.T., and Malow, R. (ed) HIV/AIDS Global Frontiers in Prevention/Intervention. New York: Routledge.

O’Leary, A., Kennedy M, Pappas-DeLuca KA, Nkete M, Beck V, Galavotti C. (2007) Association between exposure to an HIV story line in The Bold and the Beautiful and HIV-related stigma in Botswana. AIDS Education and Prevention, 19(3), 209217

Olshefsky, A.M., Zive, M.M., Scolari, R. and Zuniga, M. (2007) Promoting HIV risk awareness and testing in Latinos living on the U.S.-Mexico border: The tú no me conoces social marketing campaign, AIDS Education and Prevention, 19(5), 422435

Pallikadavath, S., Sreedharad, C., Stones, R.W. (2006) Sources of AIDS awareness among women in India. AIDS Care. 18(1), pp. 44-48.

Palmgreen, P., Noar, S.M., \& Zimmerman, R.S. (2008) Mass Media Campaigns as a Tool for HIV Prevention. In T., Edgar, S.M. Noar, and V. Freimuth (eds) Communication Perspectives on HIV/AIDS for the $21^{\text {st }}$ C. pp. 221-252. New York: Lawrence Ibrahim.

Pappas-Deluca, K.A., Kraft, J.M., Galavotti, C., Warner, L., Mooki, M., Hastings, P. et al (2008) Entertainment-Education Radio Serial Drama and Outcomes Related to HIV Testing in Botswana AIDS Education and Prevention, 20(6), 486-503

Peltzer, K. \& Promtussananon, S. (2003). Evaluation of Soul City school and mass media life skills education among junior secondary school learners in South Africa. Social Behaviour and Personality, 31(8), 825-834. 
Peretti-Watel. P., O. Yolande, D.S. Rosemary, L. France and M. Jean-Paul (2005) Attitudes and behaviours of people living with HIV/AIDS and mass media prevention campaign: A French survey. Psychology, Health and Medicine, 10(2), 215-224.

Perez, F. \& Dabis, F. (2003) HIV prevention in Latin America: reaching youth in Colombia. AIDS Care, 15(1), 77-87.

Petersen, I., Mason, A., Bhana, A., Bell, C.C., McKay, M. (2006) Mediating social representations using a cartoon narrative in the context of HIV/AIDS: the AmaQhawe Family Project in South Africa. Journal of Health Psychology, 11(2), 197-208.

Pickle, K., S.C. Quinn and J.D. Brown (2002) HIV/AIDS Coverage in Black Newspapers, 1991-1996: Implications for Health Communication and Health Education. Journal of Health Communication, Vol. 7, pp. 427-444.

Pinkerton, S.D., Dyatlov, R.V., DiFranceisco, W., Benotch, E.G., Smirnova, T.S., Dudko, V.Y. et al (2003) HIV/AIDS knowledge and attitudes of STD clinic attendees in St. Petersburg, Russia. AIDS and Behavior, 7(3), 221-228

Piot, P., Curran, W. James, Ryder, Robert, Laga, et al (1990) The global epidemiology of HIV infection: continuity, heterogeneity and change. Journal of Acquired ImmuneDeficiency Syndrome, Vol. 3.

Randolph, W., \& Viswanath, K. (2004) Lessons Learned from Public Health Mass Media Campaigns: Marketing Health in a Crowded Media World, Annual Review of Public Health, 25, 419-37.

Reeves, P.M. (2000) Coping in Cyberspace: the Impact of Internet Use on the Ability of HIV-positive Individuals to Deal with their Illness. Journal of Health Communication, Vol. 5 (supplement) pp. 47-59

Roberto, A.J. R. Zimmerman, K. Carlyle, E. Abner, P. Cupp, and G. Hansen (2007) The Effects of a Computer-Based Pregnancy, STD, and HIV Prevention Intervention: A Nine-School Trial. Health Communication, 21(2),115-124.

Romer, D. S. Sharon, C. Ralph, L. F. Salazar, P. A. Vanable, M. P. Carey et al. (2009) Mass media as an HIV-prevention strategy: using culturally sensitive messages to reduce HIV-associated sexual behaviour of at-risk African American youth. American Journal of Public Health, 99(12).

Shapiro, D., Meekers, D., and Tambashe, B. (2003) Exposure to the 'SIDA dans la Cité' AIDS prevention television series in Côte d'Ivoire, sexual risk behaviour and condom use. AIDS Care, Vol. 15, No. 3, pp. 303-314. 
Shrotri, A., Shankar, A.V., Sutar, S., Joshi, A., Suryawanshi, N., Pisal, H, et al (2003) Awareness of HIV/AIDS and household environment of pregnant women in Pune, India. INTERNATIONAL JOURNAL OF STD \& AIDS Volume: 14 Issue: 12 Pages: 835-839.

Smith, R.A., Down, E., \& Witte, K. (2007) Drama theory and entertainment education: Exploring the effects of a radio drama on behavioral intentions to limit HIV transmission in Ethiopia. Communication Monographs. 74(2) pp 133-153

Sood, S. and Nambiar, D. (2006) Comparative Cost-Effectiveness of the Components of a Behavior Change Communication Campaign on HIV/AIDS in North India. Journal of Health Communication, Vol. 11, Suppl. 2, pp. 143-162

Tambashe, B.O., Speizer, I.S., Amouzou, A., Djangone, A.M.R. (2003) Evaluation of the Psamao "Roulez Protege" mass media campaign in Burkina Faso. AIDS Education and Prevention, 15(1), 33-48.

UNAIDS - Joint United Nations Program on HIV/AIDS AIDS Epidemic Update, (2009)

Vaughan, P.W. Rogers, E.M., Singhal, A. and Swalehe, R.M. (2000) EntertainmentEducation and HIV/AIDS Prevention: A Field Experiment in Tanzania Journal of Health Communication. Vol. 5 (supplement) pp. 81-100

Vidanapathirana, J., Abramson, M.J., Forbes, A., \& Fairley, C. (2005) Mass Media Interventions for Promoting HIV Testing (Review). The Cochrane Database of Systematic Review, 3, 1-38.

Yazdi, C.A., Aschbacher, K., Arvantaja, A., Naser, H.M., Abdollahi, E., Asadi, A., et al. (2006) Knowledge, attitudes and sources of information regarding HIV/AIDS in Iranian adolescents. AIDS Care, Vol. 18, No. 8, pp. 1004-1010

Ybarra, M.L., Kiwanuka, J., Emenyonu, N., Bangsberg, D.R. (2006) Internet use among Ugandan adolescents: implications for HIV intervention. PLoS Medicine. 3(11).

Yoo, H., Lee, S.H., Kwon, B.E., Chung, S., \& Kim, S. (2005) HIV/AIDS knowledge, attitudes, related behaviors, and sources of information among Korean adolescents. The Journal of School Health, 75(10), 393-9.

Yzer, M. C., Siero, F. W., \& Buunk, B. P. (2000). Can public campaigns effectively change psychological determinants of safer sex? An evaluation of three Dutch campaigns. Health Education Research, 15, 339-352.

Zimmerman, R. S., Palmgreen, P.M., Noar, S.M., Lustria, M.L.A., Lu, H.Y. \& Horosewski, M.L. (2007) Effects of a Televised Two-City Safer Sex Mass Media Campaign 
Targeting High-Sensation-Seeking and Impulsive-Decision-Making Young Adults.

Health Education and Behaviour, 34(5), 810-826. 